\title{
Why environmental and resource economists should care about non-expected utility models
}

\author{
W. Douglass Shaw ${ }^{*}$, Richard T. Woodward ${ }^{1}$
}

Department of Agricultural Economics, Texas A\&M University, United States

Received 20 February 2006; received in revised form 2 April 2007; accepted 14 May 2007

\begin{abstract}
Experimental and theoretical analysis has shown that the conventional expected utility (EU) and subjective expected utility (SEU) models, which are linear in probabilities, have serious limitations in certain situations. We argue here that these limitations are often highly relevant to the work that environmental and natural resource economists do. We discuss some of the experimental evidence and alternatives to the SEU. We consider the theory used, the problems studied, and the methods employed by resource economists. Finally, we highlight some recent work that has begun to use some of the alternatives to the EU and SEU frameworks and discuss areas where much future work is needed.

(C) 2007 Elsevier B.V. All rights reserved.
\end{abstract}

Keywords: Environmental economics; Expected utility; Risk; Uncertainty

\section{Introduction}

The conventional expected utility (EU) model of von Neumann and Morgenstern (1944) is the central framework for the economist's analysis of choice under risk and uncertainty. For example, Graham adopted the EU framework for his classic derivation of a welfare measure under uncertainty, the option price (Graham, 1981; see discussion in Ready, 1995). Typical environmental and resource economists interested in welfare changes, non-market valuation, or Pareto Optimality, might know little more than this about risk and uncertainty. However, economists have had a good deal to say about modeling risky behavior in recent years and much of this work calls into question the basic framework of decision making under risk that is a pillar

\footnotetext{
* Corresponding author.

E-mail addresses: wdshaw@tamu.edu (W. Douglass. Shaw), r-woodward@tamu.edu (R.T. Woodward).

${ }^{1}$ Senior authorship is shared equally.
} 
of applied analysis. The question we consider here is whether environmental and resource economists would benefit from more attention to these developments. In this manuscript, the larger we (hereafter in italics) signifies this target audience of environmental, energy, and natural resource economists. We seek to bridge the gap between general risk/uncertainty economists and those of us most interested in the risk issues that are prominent today among resource economists (Chichilnisky and Heal, 1993). As used here "resource economics" is meant to encompass all of the economic issues that relate to environmental policy, natural resource extraction, and energy economics. Issues of interest to resource economists can overlap greatly with those in health economics, agricultural production and welfare, and transportation safety and efficiency.

Almost all decisions that people make involve some level of risk or uncertainty, and uncertainty is particularly pervasive in the area of resource economics. The EU framework has guided most analysis of decisions in situations of risks with known probabilities and the subjective expected utility model (SEU) of Savage (1954) can handle situations where probabilities are not known by the decision maker. These models have been successful not only because of their compelling axiomatic foundations and ability to describe economic choices, but also for the purely practical reason that their mathematical structure facilitates both theoretical and empirical analysis. Whether the probabilities are objective or subjective, the EU and SEU models can be represented as functions that are linear in the probabilities. Some more general or "non" EU (see Machina, 1987) frameworks relax the EU assumptions and lead to models that allow the decision maker to place nonlinear weights on the probabilities (e.g., Machina, 1982, 1987, 1994 or Quiggin, 1993). If we state below that a study finds behavior that is inconsistent the EU theory, we are limiting our discussion to the standard model, not to these more generalized models.

Despite obvious strength in their ties to the theory of choice, the EU and SEU models have some well-known weaknesses. Most critically, using mostly experimental evidence, researchers have often found that individuals often do not behave in a manner consistent with the EU models. We focus here on two prominent problems, frequently referred to as the Allais and Ellsberg Paradoxes. The Allais paradox refers to the tendency of individuals to overweight high-consequence lowprobability events. The Ellsberg paradox is that people regularly demonstrate an aversion to ambiguity, preferring situations with clear probabilities to those in which the probabilities are uncertain. Since the initial work of Allais (1953) and Ellsberg (1961), many experiments have been constructed to test for Allais and Ellsberg behaviors, and have frequently found it.

Because of such results it is important for us to ask whether - or at least in what circumstances of interest to resource economists - the basic EU/SEU paradigms should be retained? Below we compile a list of a number of issues frequently studied by resource economists. For some such problems (e.g., financial risks in resource management) the primary risks are probably not at the extremes and tend to be well understood. But for many other issues, such as natural catastrophes in the advent of climate change, nuclear accidents, or exposure to toxics, the salient concerns are frequently low-probability high-consequence events about which the uncertainty is great. For example, in the work on nuclear/radioactive waste risks, the experts deem mortality risks to be on the order of 2 in 10 million, while a sample of subjects thought these to be thousands of times higher (see Riddel and Shaw, 2006). In other problems, such as the valuation of an endangered species, ambiguity is pervasive. We believe, therefore, that for many of the problems in which we are interested, the conditions are exactly those in which the EU and SEU are frequently violated.

Lest the reader be thinking that all is hopeless, there are several generalizations or alternatives to the EU and SEU models, yielding theoretical results consistent with observed behavior. Some have strong normative foundations and can have good predictive power; but no one model fits all situations and behaviors. There are also behaviors that could be explained via relaxation of 
assumptions that economists usually make, but have little to do with the EU itself. We discuss such issues toward the end of the manuscript, but mainly confine ourselves to ideas related to EU axioms of rationality.

The remainder of the paper is organized as follows. First, the EU and SEU models are briefly presented along with a discussion of some evidence of systematic violations of the models' predictions. We then discuss the implications of these violations for the theory we use, the issues we study, and the methods we employ. In the final section, we state some caveats, point to other responses to these issues, and remind readers of situations where we think the EU does work well to predict behaviors.

\section{EU and SEU and the paradoxes of Allais and Ellsberg}

To begin, we differentiate between the EU and the SEU, noting that the latter recognizes the importance of subjective or perceived risks. While we might typically rely on scientific or experts' assessments of risk, psychologists (e.g., Slovic, 1987) usually assume that decisions are based on perceived or subjective assessments of risk rather than "objective ones." Savage (1954) showed that "rational" choices can always be described as arising from an expected utility calculation with the decision maker using his or her personal subjective probabilities. Subjective or perceived risks can be in accord with risk assessments calculated by the scientific community, but they can also be at opposite ends of the spectrum. Naturally, the scientific community may not be in agreement in the first place. When the subjective risks perceived by the public differ from those of the experts, conflict can arise. Table 1 highlights the conflicts that are created in the latter situation, assuming that the policy maker (government) sides with the experts' assessments of risk. We return to these conflicts below.

In both the EU and SEU models, choices are made so as to maximize the expected value of an individual's utility, say,

$$
V(\{\mathbf{x}, \mathbf{p}\})=\sum_{i=1}^{n} U\left(x_{i}\right) p_{i}
$$

Table 1

Uncertainty conflicts between the general public and policy makers/government

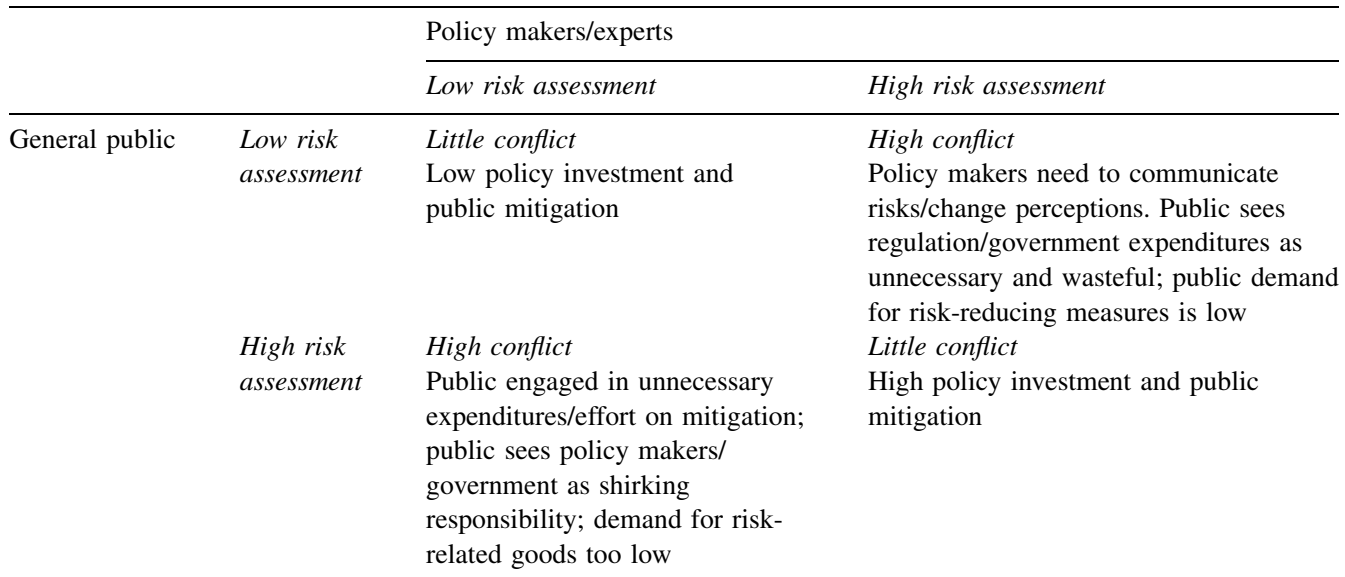


where $V(\cdot)$ is the individual's ex ante welfare, $U(\cdot)$ is the individual's ex post utility function, $\mathbf{x}_{i}$ is a vector of goods and services in the $i$ th state of the world, and $p_{i}$ is the probability that the $i$ th state of the world will actually occur. The EU formulation of von Neumann and Morgenstern (1944) assumes that the probability vector $\mathbf{p}$ is known by the decision maker. The SEU formulation of Savage (1954) makes no assumptions about the knowledge of $\mathbf{p}$, but instead shows that if a decision maker abides by a set of axioms, she will behave as if she has a set of personal or subjective probabilities. Although it does not follow from the axioms of either Savage or von Neumann and Morgenstern, agents are typically assumed to be risk averse in theoretical models, meaning that the $U$ is concave in the variable involving risk, which is most often income because the main thrust of research in the past 50 years has focused on financial risks that arise for a variety of reasons. However, in empirical applications (of which there are not that many) the assumption of risk aversion is often ignored for convenience and individuals in some estimating sample are assumed to be risk neutral.

As seen in Eq. (1), the EU and SEU are linear in the probabilities that characterize risks. In effect, the functions assume that individuals do not have preferences over probabilities themselves, only over the outcomes that result. Put another way, probability is outside, not inside the utility function. A limitation of this structure is explained by Yaari (1987):

In expected utility theory, the agent's attitude towards risk and the agent's attitude towards wealth are forever bonded together. [However,] at the level of fundamental principles, risk aversion and diminishing marginal utility of wealth, which are synonymous under expected utility theory, are horses of different colors. (p. 95).

As we will discuss below, relaxing the assumption that preferences are linear in probabilities can go a long way toward resolving many of the observed violations of the EU framework, though as we will also see below, this alone does not solve all the problems that have arisen in analyzing risk preferences (Machina, 1987).

Despite weaknesses, there are many situations in which the EU models perform well and can be used without reservations. ${ }^{2}$ These models are especially credible when probabilities are very well understood and clear to the decision maker. One thinks of a simple two-outcome toss of a fair coin, for example. Similarly, as noted by Loomes (2006b), when one option "transparently" dominates the other, decision makers rarely have difficulties making the "right" choice. A key feature of these models that relates to economic valuation is that an individual should not view or perceive of payoffs for a gamble differently from the risks of that gamble (see Loomes, 2006b). This means that there are many situations when the EU models are perfectly appropriate, or at least where connections to issues that are consistent with the traditional EU are plausible.

In Table 2 we provide a list of issues that we could think of which are important to resource economists. The columns on the right indicate our own assessments of the likely magnitude of the probability being quite small and the likelihood that ambiguity is important. As seen in Table 2, there are a number of issues that we study where risks are well-characterized; they involve neither extreme probabilities nor significant ambiguity. For these problems the EU

\footnotetext{
${ }^{2}$ A reviewer notes that several studies suggest possible inconsistencies with conventional EU models, but that in many of these studies the individual's behavior is in fact consistent with the state-dependent version of the EU, or the EU considered with transactions costs. Examples are tax evasion (Bernasconi, 1998); criminal behavior (Neilson and Winter, 1997), financial markets (Dow and Werlang, 1992; insurance against catastrophic events (Kunreuther and Pauly, 2004), and consumer willingness to partake in precautionary saving (Leland, 1968). In each instance, reasonable explanations for behavior that is consistent with the EU can be found by assuming state-dependence or adding transactions costs.
} 
Table 2

Examples of risk situations of interest to resource economists ${ }^{\mathrm{a}}$

\begin{tabular}{l} 
Situation (type of risk) \\
\hline Agricultural crop failure (financial) \\
Airline safety (mortality) \\
Arsenic in drinking water (mortality/morbidity) \\
Climate change risks \\
Extinction of Species (species mortality) \\
Financial risks in resource management \\
Flood/hurricane risks (financial, mortality) \\
Future resource prices (financial) \\
Giardosis (mainly morbidity) \\
Human health and air pollution (mortality/morbidity) \\
Invasive species (harm to native species/habitat) \\
Non-point source pollution (emissions and damages) \\
Oil exploration (lower prices/financial) \\
Radioactive/nuclear waste (mortality/morbidity) \\
Risks of enforcement of pollution non-compliance \\
Success in recreational fishing or hunting
\end{tabular}

\footnotetext{
${ }^{a}$ The check marks indicate our personal assessments of risks involved and the public perceptions of those risks. This is not intended to be conclusive, but indicative of the variety of problems studied in the area of environmental and resource economics.
}

models are probably quite adequate frameworks for our analysis. A small risk/probability issue does not in itself mean that the EU will fail. However, if people, no matter how hard we try to communicate these small risks to them, simply cannot process the information in such a way as to know how to make decisions, then the first step toward failure of the EU and SEU has been taken.

Violations of the basic axioms of the EU and SEU models have been identified by many researchers including Kahneman and Tversky (1979), Loomes and Sugden (1982), and others. ${ }^{3}$ A classic outcome is preference reversal when encountering similarity, known as the common ratio effect (see Starmer, 2000; Loomes, 2006b). This literature is too vast to present many cases here, but Starmer (2000) provides a good summary up to the date his paper was published. The Allais and Ellsberg paradoxes get particular attention because they are where the largest body of alternative risk research has been conducted and where the possibilities for improving analysis in resource economics seem to be the greatest.

In his path-breaking analysis, Allais (1953) showed that the assumption that utility is linear in the probabilities is not always satisfied. The Allais paradox is that decision makers often do not treat probabilistic outcomes or events in the standard additive manner as required in (1). Instead, dis-proportionally more weight is given to low-probability high-consequence events. Intuitively, we might easily come up with reasons why the magnitude of the probability would matter when we are making a choice. Such reasons give way to the concepts of a "certainty" effect (i.e., I feel that $99 \%$ is virtually certain, so why bother with a policy that pushes the probability from this to $100 \%$ ? Conversely, I want to be absolutely certain and $99 \%$ leaves some doubt, so I care much

${ }^{3}$ See Anand (1993) for a review. 
more about this increase of $1 \%$ than I do for the same $1 \%$ increase from 50 to $51 \%$ ). Allais paved the way for work on the impact of scaling down probabilities associated with lotteries, with the frequent result that such scaling flips preferences, when EU theory says that it should not. Such preferences are inconsistent with the EU because they violate Savage's independence axiom. Closely related is the possibility that people behave as if they weight probabilities.

\section{Probability weighting functions: some evidence}

There is evidence that people make decisions under conditions of risk as if they are actually weighting probabilities $(p)$ that characterize risks. If a weight, $w(p)$, exists over a spectrum of probabilities, it is possible to map out a probability weighting function (PWF). We more formally introduce these below, but note in this section that when the PWF is nonlinear, departures from the original von-Neumann-Morgenstern utility function (e.g., Quizon et al., 1984), and alternatives are worth considering. This kind of evidence of nonlinear PWFs is consistent with Allais' (1953) concerns, and both the common consequence, and common ratio effects, which are damaging for the basic EU.

To our knowledge, the evidence on the existence of PWFs comes from laboratory experiments which makes sense because uncovering the shape of a PWF for an individual can be somewhat difficult. It can be done using a variety of approaches, with the recent literature favoring the trade-off approach (Wakker and Deneffe, 1996). ${ }^{4}$ Empirical work has elicited PWFs for mostly monetary, such as Gonzalez and Wu (1999), and much less frequently lifeduration, gambles, with a mixture of outcomes (see Bleichrodt and Pinto, 2000; or Wakker and Deneffe, 1996). For example, the PWF in the monetary-gamble domain is concave for low probabilities and convex for high probabilities with the weight equivalent to the actual probability ranging between 0.3 and 0.5 (Prelec, 1999). Less is known about non-monetary gambles and PWFs.

Wakker and Deneffe (1996) use a trade-off method mostly applied to financial gambles, but part of their analysis evaluates the way that a pool of psychology and $\mathrm{PhD}$ students viewed risks associated with surgical operations to cure them of unknown health risks associated with a disease they were to imagine they had. Subjects are not told the exact risks of carrying an unfavorable disease, only that they are young and that their probability of carrying the disease is expected to be smaller than for older people, $66 \%$ of whom carry the disease. Based on their results, they conclude that a higher risk aversion for life-duration is due to stronger deviations from expected utility, rather than due to curvature of the utility function. ${ }^{5}$

Other experiments are set up to see if risk preferences stay constant in a manner consistent with linear probability utility functions. They often do not. For example, Bosch-Domènech and Silvestre (1999) find that risk attitudes vary with the level of the endowment for some of their experimental subjects, revealed by subjects' decisions to insure their incomes. A large number of experimental economics studies evaluate when and how the EU models fail and when they succeed (e.g., Hogarth and Kunreuther, 1985). Such experimental efforts are by far the most

\footnotetext{
${ }^{4}$ Wakker and Deneffe (1996) conclude that the "trade-off" approach has distinct advantages over the other methods (the certainty-equivalent (CE), direct scaling, and probability-equivalent methods).

${ }^{5}$ Results are also based on an experiment involving monetary gambles. It is also worth a reminder here that all of the subjects used by Wakker and Deneffe (1996) were, as they put it, "well acquainted with probabilities and expectations." [p. 1135].
} 
common empirical approach in the literature that has been previously applied to test for violations. ${ }^{6}$ Thorough reviews of this literature are available elsewhere. ${ }^{7}$ Experiments have mainly involved choices of financial lotteries, often with incentives given for making a choice consistent with our own understanding of decision making under risks.

Experiments that follow from the work of Allais have found that the EU model tends to predict behavior quite well when the decision problem involves probabilities in the "mid-range." However, when faced with small probabilities, nonlinear weighting "is empirically important in explaining choice behavior" (Harless and Camerer, 1994, p. 1285). The basic EU model is also not very good at explaining choices when individuals are faced with losses as well as gains (Quiggin, 1993 p. 140), as it does not differentiate between these.

\subsection{Ambiguity}

Ellsberg's paradox relates to uncertainty that cannot be reduced to simple probabilities. This kind of uncertainty, which we well refer to as ambiguity, is closely related to Knightian uncertainty (Knight, 1921) and Shackle's similar concepts (1952, 1969). Ambiguity involves more than just a PWF. There is no room for true ambiguity in the EU models. Implicit in the SEU is a Bayesian approach in which uncertainty over the probability distribution, $\mathbf{p}$, can be expressed as second-order probability distributions, which can then be additively reduced to a single probability distribution. However, as Ellsberg (1961) showed experimentally, individuals do not follow this reductionist procedure; ambiguity does affect preferences. Camerer and Weber (1992) describe the nature of the ambiguity problem as follows: Suppose you flip a coin 1000 times and get 500 heads. Then take a second coin and flip it twice yielding one head and one tail. There is no objective reason to believe that the probability of heads using the second coin is any different from that of the first. Yet,

$[\mathrm{m}]$ any people ... prefer to bet on the first coin, because they are more confident or certain that the first coin is fair. Ambiguity about probability creates a kind of risk in betting on the second coin - the risk of having the wrong belief. SEU effectively requires that decision makers be indifferent towards such a risk. (p. 326)

This systematic aversion to ambiguity cannot be reconciled with the EU or SEU models. There are many "Ellsberg-type" studies showing the existence of ambiguity aversion in preferences.

Some psychologists today have offered two competing hypotheses for the formation of ambiguity: comparative ignorance (Fox and Tversky, 1995; Fox and Weber, 2002; Chow and Sarin, 2001) and the competence hypothesis (Heath and Tversky, 1991; Keppe and Weber, 1995).

\footnotetext{
${ }^{6}$ To be fair here, we note that Karni and Safra (1995) argue that experimental economics cannot be a decisive tool to use when it comes to eliciting subjective risks. They offer a proof that subjective risk estimates obtained when the subjects have a stake in outcomes pertaining to total wealth are simply impossible to elicit. Their strong-sounding conclusion is softened when outcomes are couched as losses, as many environmental economists might express environmental damage, or gains/improvements, as many might express the environmental improvements that have arisen because of the Clean Air Act and the like. Karni and Safra's conclusion therefore does not negate all of the conclusions that flow from studies of subjective risks. Still, it would be more convincing if evidence of the failures of the EU framework came not from the laboratory, but from observed behavior of economic agents.

${ }^{7}$ Anand (1993) provides a good overview of the experimental work, breaking it down significantly more than we have here. Harless and Camerer (1994) survey and synthesize the experimental evidence related to Allais-type behavior, and Camerer and Weber (1992) review the studies that have addressed Ellsberg-type behavior and ambiguity. Shaw et al. (2005) survey the literature with a focus on valuation.
} 
In the first hypothesis, an individual's sense of ambiguity grows when he or she is presented with the fact that there is some set of information that is better than what they have when it is vague: their vague information conflicts with information that appears to be clear. When experts about risk disagree, individuals can place disproportionate weights on high risk outcomes; Viscusi et al. (1999) demonstrate this using health risks posed by cigarette smoke. In contrast, the competence hypothesis allows individuals who are particularly knowledgeable or well informed about something (the outcome of a football game) to overcome any feelings of ambiguity. In the studies by Heath and Tversky (1991) and Fox and Tversky (1995), experiments are used, and controlled bets in two settings reveal tendencies to bet on clear rather than vague probabilities. When individuals exhibit a good degree of ambiguity aversion, they tend to pay to avoid it.

Experimental work on ambiguity has focused on two specific and important issues: the distinction between ambiguity and risk, and the degree of aversion to ambiguity. To distinguish these, we use the term event risk to refer to the usual uncertainty about an event or outcome (e.g., the risk of getting cancer from a substance in drinking water) and the term ambiguity to refer to uncertainty about the risk itself (e.g., the uncertainty about what the actual probability of getting cancer is). In reviewing the literature on ambiguity, Camerer and Weber (1992) found no correlation between risk attitudes and ambiguity attitudes. They also found the existence of "substantial premiums to avoid ambiguity - around 10-20\% of expected value or expected probability" (p. 340). Ambiguity, therefore, cannot only be separate from event risk, but is economically important.

Finally, in one early, non-experimental, and seminal empirical study Kunreuther (1976) finds such evidence among thousands of people interviewed in earthquake and flood-prone areas, including a pool of both insured, and uninsured respondents. He concludes that neither group's behavior can be explained via the "standard" [EU] framework. While part of the sample does not have enough information, and blame rests there, he concludes that even those who do "frequently behave in a manner inconsistent with what would be predicted by [EU] theory." [Kunreuther, 1976, p. 255]. There are very few such empirical studies.

\section{Some recent non-experimental applications of, and evidence, from non-EU models}

Most of the impetus for non-EU models has come from experimental work because laboratory settings allow sufficient controls to test the EU axioms. It is much more difficult to find empirical evidence (not just theoretical) that supports non-EU frameworks, involving "real-world" phenomena (from natural experiments or survey data on intended, or actual behaviors). Actually proving a violation of the SEU in the real world is much more difficult than in the laboratory; naturally, carefully done empirical work only fails to disprove something.

Nuclear waste storage is a setting where work has been done to explore whether individuals' preferences under risk are consistent with standard EU models. Nuclear waste storage is a longterm proposition: high level radioactive wastes must be stored safely for about 10,000 years before their toxic effects diminish to a safe level through a natural decay process. Using assessments of most physical scientists who have worked on the Yucca Mountain Repository project, the long- and short-term mortality risks appear to be extremely low - on the order of 1 or 2 in 10 million. However, even when told this, subjects in a sample believed such risks to be thousands of times higher than the government scientists, classic evidence of failure to comprehend the extremely low probabilities. In one of the only studies using field survey data that we know of, estimated models that depart from the EU are statistically preferred to ones that are more restrictive. The statistical test involves significance of terms that result when incorporating nonlinear probabilities. The preferences of sample individuals in these studies 
exhibit evidence of ambiguity aversion (Riddel and Shaw, 2003; Riddel et al., 2003; Riddel and Shaw, 2006).

Another empirical study that provides evidence supporting use of a non-EU framework is Cameron's (2005) study on climate change. Again using survey data, and specific functional forms for indirect expected utility functions that allow for nonlinear probability weighting, Cameron finds that individual option prices are affected by the dispersion of an individual's subjective probabilities over future environmental quality. This dispersion term is incorporated using the squared deviation between realized temperature and its ex ante expected value. Such preferences do not arise in the linear-in probabilities EU.

Finally, in Baker et al. (2007), we interviewed a small sample of people who were displaced by the major hurricanes, Katrina and Rita. Subjects were asked to state their subjective risk of a hurricane of similar magnitude to Katrina striking the area they came from (most are from New Orleans), after being told that the experts believe this probability to be around $10 \%$. Even after the subjects were walked through educational material (presented to them on a laptop computer with pictures and easy to read text), the average subjective risk for the sample is close to $50 \%$. Of particular interest in our results is the "unsure" explanatory variable. Respondents were asked after their final report of subjective risk whether they were sure or unsure of their risk estimate. On average, stated risks by individuals who are unsure were $20 \%$ higher than those who were more confident. This result is consistent with an aversion to ambiguity as operationalized by Gilboa-Schmeidler's Maxmin Expected Utility which we discuss below.

There are also several theoretical concerns regarding the EU framework, though we are not offering these as "evidence" that the EU fails. For example, consider the problem of insurance choices in the EU framework. Quiggin (1993 pp. 80-81) shows that it would never be EUoptimal to purchase full insurance if rates are actuarially unfair and the utility function is smooth. Intuitively, this is because, in the neighborhood of certainty, the EU preferences are risk neutral so that at the limit agents would prefer to bear some portion of the risk. While alternative explanations for observed full-insurance in the market are possible, Segal and Spivak (1990) show that nonlinear PWFs preferences can explain the purchase of complete insurance. Quiggin (1993) summarizes the result: "even if first order risk aversion is too weak to induce the purchase of insurance, second-order risk aversion [nonlinear weighting of probabilities] may lead to a preference for insurance" (p. 81). The ability to discriminate between preferences over the outcomes and preferences over the probabilities in the problem itself, therefore, can prove useful in understanding observed behavior.

We see, therefore, that in both the laboratory and in a few select survey settings the EU models cannot describe all behavior of economic agents. Where economists go from there, however, is not transparent. There have been two principal responses to the experimental evidence. The first is to treat the results as "phenomena" instead of "paradoxes" (Howard, 1992) which require no more of a re-evaluation of the EU models than people's confusion by optical illusions require us to invent new notions of distance (Varian, 1992, p. 194; McFadden, 1999). The second response has been to look for theoretical alternatives to the EU and SEU models that can explain the behavioral patterns found in the experimental work, yet retain much of the theoretical appeal and empirical tractability of the EU and SEU models. We examine two of these alternatives in the next section.

\section{Solutions? Alternatives to the EU models}

One might first simply conclude from the above discussion about risks that the EU and SEU will always perform well if researchers just keep pushing people hard enough in risk 
communication exercises. However, there are several reasons this is not the case. First, as indicated above, scientists may not know risks much better than anyone else, leaving doubt about what they are. An example of this is what is known about the human health risks of ingesting arsenic for lower arsenic concentrations, below 50 parts per billion (see Shaw et al., 2006). In surveys and experiments the research is supposed to be truthful with subjects; analysts are obligated to pass on this scientific doubt. Second, understanding risks may take time. For example, consider the assumption that we make that the following two lotteries (denoted with payoff, probability) are equivalent: $(30,1 / 2 ; 40,1 / 2)$ and $(30,1 / 4 ; 30,1 / 4 ; 40,1 / 2)$, which is key to development of defining preference changes (Machina, 2001). Well educated people immediately see the equivalence, but it may take time to convey this to those less well educated. There is a limit to what people can take in and process, and it is well known that respondents to surveys and experimental subjects become fatigued after time, so pushing harder in risk communication may lead to some gain on one hand, but losses in mental acuteness later on, perhaps when payoffs are being evaluated. If people just do not "get" probabilities, they may behave in manners that indicate this. ${ }^{8}$

In the next section, we present two alternative risk models that seem particularly promising for use in environmental economics: the rank dependent expected utility model, and the maxmin EU model. Both retain much of the structure of the EU and SEU frameworks, yet are able to explain more of the experimental evidence than these models would. ${ }^{9}$ This treatment is by no means exhaustive; we are excluding for example Kahneman and Tversky's (1979) prospect theory, Loomes and Sugden's (1982) regret theory, Viscusi's prospective reference theory (1989), and Loomes' (2006b) perceived relative advantage model (PRAM).

\subsection{The RDEU model}

The rank dependent expected utility model (RDEU) that was originally proposed by Quiggin (1982), has also been explored by Yaari (1987), and is closely related to the models of Schmeidler (1989) and Gilboa (1987). Originally developed to explain the Allais paradox, the RDEU model allows probabilities to enter nonlinearly into an individual's objective function. Because it preserves first-order stochastic dominance, Machina (1994, p. 1237) called the RDEU the first "successful" model with nonlinear probabilities.

The RDEU model (presented in depth in Quiggin, 1993), is typically applied in problems with well-defined probabilities, but is not restricted to that context. ${ }^{10}$ Following Quiggin (1993), the RDEU model is most easily presented in terms of a single lottery in which there are $n$ possible

\footnotetext{
${ }^{8}$ Skeptics might say that if the experiment just incorporates incentives for getting risks in line with the experts, then the PWF for an individual will become linear, i.e. people are EU maximizers. For example, Harrison and Rutström (2006) pay subjects for correctly ranking mortality risks the same way that the data from sources like the Center for Disease Control do, thereby showing that discrepancies between the CDC rankings and the subjects are small. This again supports the notion that EU modeling is more plausible when risks (here for other, anonymous people) are well-understood. We are not sure of the usefulness of this experimental result on ranking risks: for one, their incentive scheme might do little to change risk rankings when the mortality risks are personal rather than for other people. The PWF for environmental risks is (to our knowledge) an unexplored empirical question.

${ }^{9}$ Readers are referred to Kelsey and Quiggin (1992), Camerer and Weber (1992), Quiggin (1993) and Harless and Camerer (1994) for much broader reviews of the literature and perspectives on the relative utility of different models. ${ }^{10}$ The RDEU model has, however, also been applied to conditions of ambiguity by Segal (1987), who uses the RDEU to apply to second-order probability distributions. Similarly, the model is quite similar to the models of Schmeidler (1989) and Gilboa (1987) that axiomatize a model that uses Choquet integration when decision makers are faced with ambiguity.
} 
outcomes, $x_{i} ; i=1, \ldots, n$, which are ordered from worst $(i=1)$ to best $(i=n)$. Each outcome $x_{i}$ has a known probability $p_{i}$ so that the probability of achieving an outcome of $x_{i}$ or worse is written $F\left(x_{i}\right)=\sum_{j=1}^{i} p_{j}$. The RDEU functional is of the form:

$$
V(\{\mathbf{x}, \mathbf{p}\})=\sum_{i=1}^{n} U\left(x_{i}\right) h_{i}(\mathbf{p})
$$

where,

$$
h_{i}(\mathbf{p})=q\left(F\left(x_{i}\right)\right)-q\left(F\left(x_{i-1}\right)\right) .
$$

The function $q$ is monotonically increasing with $q(0)=0$ and $q(1)=1 .{ }^{11}$ Note that $h_{i}(\mathbf{p})$ is not a simple transformation of $p_{i}$, but is instead a function of the cumulative distribution at $x_{i}$ and $x_{i-1} \cdot{ }^{12}$ The transformation function $q(\cdot)$ is where the RDEU model generalizes EU analysis. If $q(F)=F$, then the RDEU is equivalent to EU. Quiggin (1982) proposed an $S$-shaped function that was generalized by Tversky and Kahneman (1992) to take the form

$$
q(F)=\frac{F^{\gamma}}{\left(F^{\gamma}+(1-F)^{\gamma}\right)^{1 / \gamma}}
$$

For $0<\gamma<1$, this specification gives more weight to the worst and best events than would be implied by the probabilities of such events, i.e., $h_{i}(\mathbf{p})>p_{i}$ for $i$ close to 1 or $n$. Others (e.g., Chew et al., 1987) have assumed that $q$ would be concave, which is a natural extension of the notion of risk aversion to the RDEU model. Although the RDEU adds significant nonlinear complexity to the specification of an individual's preferences, it can involve as little as only one additional parameter compared to an EU model.

RDEU can explain much of the evidence that has been generated in experimental studies that conflict with the EU and SEU models. ${ }^{13}$ As noted above, the nonlinear weights on objectively known probabilities that are observed in Allais-type behavior are easily captured by the RDEU. To explain Ellsberg-type behavior in conditions of ambiguity, in the RDEU "the decision weights are interpreted as non-additive subjective probabilities" (Quiggin, 1993, p. 72; see also Epstein, 1999). Hence, this single mathematical formulation can be used to represent choices arising from nonlinear weighting of extreme events or ambiguity aversion. Still, because of its close similarities to the EU model, many of the standard results can be directly applied even if decision makers are thought to be RDEU maximizers (e.g., Quiggin, 1991).

The function in (4) allows for lower and upper subadditivity. ${ }^{14}$ It takes an inverse $S$-shape for values of $\gamma$ between 0.27 and 1 , and the parameter may be different for risks involving gains and losses. Bleichrodt and Pinto (2000) simply state that lower subadditivity, for example, means a lower interval has more impact on a decision maker than an intermediate range of probabilities.

\footnotetext{
11 The assumption that $q(1)=1$ is relaxed by Dow and Werlang (1992) to address the issue of ambiguity.

12 This property is what guarantees that the stochastic dominance is satisfied and is roughly equivalent to Choquet integration that has been axiomatically derived by Schmeidler (1989).

${ }^{13}$ Harless and Camerer (1994) point out, however, that compared to other models the RDEU framework is not very discriminating so that tests of the model have relatively low power.

${ }^{14}$ The weighting function satisfies subadditivity if there exist constants $\varepsilon \geq 0$ and $\varepsilon^{\prime} \geq 0$ such that $w(q) \geq w(p+q)-w(p)$ whenever $p+q \leq 1-\varepsilon$. Here $q$ is a lower value for a probability and $p$ is a higher one. A similar expression pertains to upper subadditivity. See Fig. 2 in the paper by Tversky and Wakker (1995). Without reproducing that graph here, the lower subadditivity condition basically implies a very steep portion of the weighting function near zero, with a flattening in the middle portion.
} 
Still, it may well be that for each individual in a sample, the weighting function in Eq. (4) varies: there is not one weighting function that best approximates relationships for everyone in the sample. Gonzalez and Wu (1999) suggest a two-parameter specification for the probability weighting function, and also suggest a non-parametric approach, making no assumptions about the form. The latter would allow each individual to exhibit their own weighting function. Their evidence supports the two-parameter weighting function, and for their subjects the report an inverse $S$-shape appears "to be a regularity that holds both at the aggregate level and for individual subjects" [Gonzalez and Wu, 1999, p. 149].

Like conventional EU models, the RDEU has been and is being tested in the laboratory. A test of the RDEU is whether co-monotonic independence holds, which allows violations of independence under some circumstances. Tests of the RDEU versus EU have resulted in mixed evidence (e.g., Wakker et al., 1994). Oliver (2003) tests the performance of the RDEU versus the EU on staff recruited from a health care facility in London. The exact experimental procedures are not well explained in the paper, but appear consistent with classifying this study as a typical laboratory experiment. Subjects are presented with health-care outcomes, treatment options, and life-durations, and data are used to test the Allais paradox or violations of independence. The author concludes that when one option is certain, the RDEU explains violations of the EU. However, when all options involve uncertainty, he concludes there is no evidence supporting the RDEU as a better descriptive theory than the EU (or vice versa).

\subsection{Maxmin expected utility (MMEU)}

The second model that we highlight here is the maxmin expected utility (MMEU) model developed by Gilboa and Schmeidler (1989). ${ }^{15}$ MMEU, was developed to address the Ellsberg paradox and it formalizes the criterion of Wald (1950) and generalizes the axiomatic work of Arrow and Hurwicz (1972). Like the SEU model, MMEU does not make immediate assumptions of exogenously given probabilities, but assumes that individuals derive probabilities based on their personal experience. The MMEU differs from the SEU in the presentation of the independence axiom and through the introduction of an axiom of uncertainty aversion. As a result of these subtle differences, while SEU-rational agents would act as if they possess a unique probability distribution over the set of outcomes, $\mathbf{p}$, MMEU-rational agents make choices based on a non-unique set of probability distributions, say, $\mathbf{C}=\{\mathbf{p}\}$. For example, in a two-outcome problem, the MMEU maximizer may believe that the probability of success is between $30 \%$ and $40 \%$, but he or she is unable (or unwilling) to place a second-order probability ranking over this range of probabilities.

A decision maker following the MMEU axioms, including uncertainty aversion, would maximize the minimum expected utility. In other words, if utility is a function of choices $\mathbf{z}$ and the state $x$ and the individual is ambiguous over a set of probability distributions, $\mathbf{C}$, then $\mathbf{z}$ is preferred to $\mathbf{z}^{\prime}$ if

$$
\min _{\mathbf{p} \in \mathbf{C}} E_{\mathbf{p}} U(z, x) \geq \min _{\mathbf{p} \in \mathbf{C}} E_{\mathbf{p}} U\left(\mathbf{z}^{\prime}, x\right)
$$

where $E_{\mathbf{p}}$ is the expectation based on the probability distribution $\mathbf{p} \in \mathbf{C}$. At one extreme, if $\mathbf{C}$ is composed of a single probability distribution then the MMEU criterion coincides with SEU

${ }^{15}$ A similar framework has also been proposed by Kelsey (1993). 
theory. At the other extreme, if the decision maker is entirely ignorant of the possible probability distributions, then the criterion in this case coincides with Wald's maximin criterion.

The RDEU and MMEU models for choice under uncertainty are two leading contenders in the search for improved frameworks for choice under uncertainty. Still, Harless and Camerer's 1994 conclusion appears to still hold true today-there are no clear winners; some theories explain little behavior while others cannot discriminate between behavior consistent with the model and purely random choices. Some models have strong axiomatic foundations while others are essentially ad hoc. Loomes's (2006b) recent work echoes these concerns about the lack of a general model. Despite this unresolved (or unresolvable) state of affairs, non-EU models are already being found useful in applied economic analysis. For environmental and resource economists, we see important implications for the theory that underlies our work, in the issues that we study, and in the methods that we employ.

\section{Non-EU analysis in resource economics: the theory we use}

Like it or not, benefit-cost analysis (BCA) is one of the most basic tools we employ. With conditions of uncertainty, there is still some debate about how BCA should proceed (Graham, 1981, 1992; Ready, 1993, 1995; Chavas and Mullarkey, 2002). However, it is seems there is growing consensus that, using the definitions of Hammond (1981), it is appropriate to use an ex ante measure, i.e., based on individual's willingness to pay in an uncertain world, as opposed to an expected ex post measure in welfare analysis, or at least BCA.

Although it appears that the profession has largely accepted this ex ante perspective, the question of which ex ante welfare measure is appropriate has not been resolved formally, and may in fact be unresolvable. Hammond (1981) spells out the contrasting points of view. On the one hand, a respect for "consumer sovereignty" favors an ex ante approach. As summarized by Krupnick et al. (1993, p. 1274, emphasis added), "since damages are estimated based on individuals' willingness to pay to avoid risks, it is more appropriate to estimate damages based on lay perceptions of risk since their willingness to pay is based on their perceptions."

On the other hand, the fact that "individuals misperceive the probabilities of certain events," suggests that perhaps a benevolent (paternalistic) planner might be in a better position to advance the interests of the misguided public. From this perspective the analytical objective would be to identify the expected impacts of policies after the fact, i.e., the expected ex post value. The alternative perspective is described by Loomes (2006a):

the best estimate of the loss of wellbeing entailed by becoming diabetic, or suffering nonfatal injuries in a road accident, or having a new housing development built on nearby farmland can be obtained by measuring what life is actually like for people who have those experiences compared with people who have not.

While not recommending an ex post approach, Crocker et al. (1991, p. 6) present the case of an environmental danger that is not sufficiently appreciated by the public, "Does the regulator ban the environmental danger or allow individuals to use their own discretion? The dilemma is to balance the trade-off between preserving individual freedom of choice and maintaining public safety."

As discussed above, individuals sometimes place more or less weight on risks than would be merited based on the best available estimates of the probabilities. As highlighted in Table 1, this can lead to conflicts if policy-makers side with the experts and the general public's perceptions fall at the other end of the spectrum. Consider the control of risks associated with nuclear waste 
disposal (again, as included in Table 2). Two options might be available: Plan A with very small risks and high costs, and Plan B with lower risks and extraordinarily high cost. Based on expert assessment of the risks, standard benefit-cost analysis may favor a Plan A, exposing the population surrounding the transportation route to very small risks of severe consequences. The public, however, because of ambiguity surrounding the risks (for lack of information) or because of tendency to overweight low-probability high-consequence events, may be willing to pay extraordinary costs of Plan B to reduce risks even further. Conflict will arise if Plan A is adopted despite the fact that, based on best available evidence, Plan B does not pass a benefit costs test and would, on average, be a mis-allocation of resources.

Policy analysts, therefore, have a clear choice. Respect consumer sovereignty, or watch out for the best interests of the public, ex post. The notion of consumer sovereignty is a deeply embedded tradition in economics, and it is part of the Pareto criterion. Even in the general welfare economics tradition of Kaldor (1939) and Hicks (1939), the notion that a government's choices should be built on the preferences of individuals is widely accepted. Yet if non-EU preferences prevail, there will be a conflict between what is preferred by individuals and what is, ex post and on average, in their best interests. It is not even clear how choices would be made by elected officials; if most relevant uncertainty is resolved within the electoral cycle, then respecting consumer preferences would be politically wise, while if uncertainty is resolved outside the political cycle, then the expected ex post perspective is politically preferred.

The answer to this question also has important implications for how we carry out non-market valuation (often used to obtain the benefits side in BCA) and policy analysis. Stated preference valuation methods would typically capture the ex ante preferences of individuals. If the individual's preferences are RDEU as defined above, a policy $z$ that affects the vector of goods and services $\mathbf{x}$ would yield ex ante welfare $V(z)=\sum_{i=1}^{n} U\left(\mathbf{x}_{i}(z)\right) h_{i}(\mathbf{p})$. The monetary value found in stated preference methods would be a monotonic function of $V(z)$. On the other hand, as noted in the Loomes quote above, revealed-preference data are often observed after the state of nature is revealed, so that the valuation effort is related to the expected ex post utility function, $U\left(\mathbf{x}_{i}(z)\right){ }^{16}$

Prior to beginning a valuation exercise, therefore, it is important to resolve the question of whether values should capture ex ante preferences or expected ex post outcomes. Given that there are legitimate questions about whether an ex ante or expected ex post measures are appropriate, the most flexible approach would be for applied benefit-cost analysts to carry out both, and to pay specific attention to discrepancies that arise because of non-EU preferences. If such complete analysis is not feasible, then the perspective maintained should be stated explicitly.

\section{A role for non-EU analysis: some issues we study}

As highlighted in Table 2, there are many problems that we study where conditions are ripe for EU axiom violations to occur. First, as noted by Toman (1998), non-SEU models might be appropriate when evaluating the climate change policies. Putting it more strongly, Heal and Kriström (2002) state:

Even if we knew exactly what the climate would be in 2050 , we still would face major economic uncertainties because we currently do not know how altered climate states map into human welfare. (p. 4).

\footnotetext{
${ }^{16}$ Notice that this also suggests a reason why convergent validity may not be achieved.
} 
Simply recognizing uncertainty and incorporating it into a standard climate change model makes it optimal to more aggressively seek to reduce warming (Ayong Le Kama and Schubert, 2004). ${ }^{17}$ However, the degree of ambiguity about the consequences of climate change is substantial among climate change scientists, prompting Cameron (2005) to incorporate ambiguity into her modeling of behavior related to climate change. Woodward and Bishop (1997) also explicitly address ambiguity, considering the case of a social planner who uses the maximin framework of Arrow and Hurwicz (1972). Whether individuals place nonlinear weights on probabilities or are averse to ambiguity, the general result would be the same - compared to EU preferences, such individuals would place more weight on the most severe consequences of global warming. These non-SEU frameworks, therefore, provide a justification for more aggressive climate policies, akin to policies that follow from the precautionary principle.

Another issue for which non-EU preferences could play a role is in assessing the risks of extreme natural events such as floods, droughts, some health risks, and other catastrophes. Several studies indicate that markets in insurance are not working correctly in these areas (e.g., Chivers and Flores, 2002; Kunreuther and Pauly, 2004). As a specific and probably poorly known example, White (2001) suggests that options market for catastrophes have not worked as well as had been hoped. The recent analysis of nuclear wastes and responses to extremely low probabilities as risks (Riddel and Shaw, 2006) sheds light on how people react to catastrophic/low probability events.

As a final issue, consider all of those risks that might be characterized as being endogenous to the individual. Several authors have argued that risks are actually endogenous because individuals can self-protect or mitigate to reduce the severity of an outcome that has negative consequences (e.g., Shogren and Crocker, 1991). As Heal and Kriström (2002) note, climate change risks are "generated by our own activities," at least to some extent. Using another example from the literature, the probability of lightening striking a home is exogenously determined, but the probability of the house burning down is not. Yet, economists are generally more interested in health outcomes (injuries and death) than the lightning event itself. If that is the case, then one would not wish to use objectively-determined probabilities in an EU model, though it may be possible to map from the probability of lightening to the probability of a health outcome. Quiggin (1992) added considerable detail to the original framework that Shogren and Crocker (1991) laid out, and in Quiggin (2002) shows the applicability of the general concepts to a state-contingent approach, which is then applicable to non-expected utility formulations. Ideas how endogenous risk can be incorporated into econometric models are presented below.

\section{A role for non-EU analysis: the methods we employ}

From the tools of non-market valuation methods to dynamic optimization, there is a need for determining how non-EU preferences should be incorporated into the tools of our trade. As an example, Viscusi (1997) reports on failure in rational Bayesian learning and alarmist reactions to health risks associated with air pollution. Basic work on risk preferences related to environmental and resource issues needs to be done, and we should be trying to find the shape of the PWF if we think it might be nonlinear. Such shapes have been shown to depend on the outcome domain (Bleichrodt and Pinto, 2000).

\footnotetext{
${ }^{17}$ Howarth (1997) notes that there is an additional dimension to uncertainty: not only are we uncertain about the consequences of climate change, but also about the preferences of future generations.
} 
For example, Heal and Kriström (2002) noted in 1993 that ". . . the question of risk aversion [had] not been studied in the context of climate change." [p. 14]. To our knowledge, it still has not been. Other examples for resource economists follow below.

\subsection{Valuation}

Though it sometimes offends the sensibility of theoretical micro-economists, preferences estimated using stated choice data are often used to estimate values. This is more common with situations where certainty is assumed than when risk/uncertainty is allowed, but there are estimates of welfare under conditions of uncertainty that exist, mostly based on the EU framework. If actual preferences are not consistent with EU framework, then the resulting estimated values will be biased. In his generally critical review of non-EU models, McFadden (1999, p. 97) notes that the standard models "does not apply universally, or even regularly, to choices made in non-market contexts." He goes on to note, "Nowhere has this been more evident than in economists' attempts to value non-use public goods, such as endangered species or wilderness areas." Yet most applications that we know of in environmental economics stick closely to the basic EU framework's assumptions in analyzing choices (see Shaw et al., 2005, for a summary). Recent exploration of non-EU preferences, and particularly, allowance for choice under ambiguity, can be found in the food-safety and health risk literature (see Kivi and Shogren, 2005; Shaw, Nayga and Silva, 2006).

As noted above, econometric methods can be used to test for the structure of the expected utility function, allowing determination of whether probabilities enter linearly or not (Riddel and Shaw (2006, 2003) and Cameron (2005)). The resulting ex ante welfare measures in these studies takes a form that is different than the usual option price equation that would be derived in the linear-in-probabilities form of Graham (1981). If nonlinear probabilities or ambiguity aversion affects individuals' preferences, then these alternative forms should be recognized in the valuation models that are employed. It is relatively straight-forward to discern whether subjects feel uncertain about the risks that they face, and some survey questionnaires even induce ambiguity, so it is likely impossible to avoid.

Another issue in valuation involving uncertainty is when respondents to contingent valuation questions say they do not really know the answers to questions, or at least they are uncertain about the exact magnitude of the value of something. In some cases, from the individual's point of view, this may overlap with actual risk, but this need not be the case. An interesting approach is to allow for "fuzzy" logic or math in the derivation of the resulting values in this context. Recently van Kooten et al. (2001) and Sun and van Kooten (2005) have demonstrated that fuzzy set theory may be used in lieu of the other approaches to dealing with uncertainty values. Loomes (2006a), on the other hand, interprets all contingent valuation through a skeptical psychological lens that questions the ability of individuals to provide meaningful translation of anticipated events into monetary measures of willingness to pay. What all of these approaches have in common is that they relax, at least to some degree, the assumption that individuals have EU type preferences.

It is also possible that the shortcomings of the EU model might be behind the frequently observed differences behind estimates of willingness to pay and willingness to accept that are obtained in a context of risk. Horowitz and McConnell (2003) have argued that the magnitude of the WTA/WTP ratios found in the literature are "implausibly high" and "reject the claim that observed WTA/WTP ratios are consistent with a standard neoclassical model." Empirical evidence that the WTA-WTP disparity may be related to non-EU preferences is mixed. With a small sample of respondents, Brown (2004) found some evidence that ambiguity may be related 
to the divergence, but did not formally test this. Eisenberger and Weber (1995) use a simple event lottery, allowing experimental subjects to specify their maximum WTP to participate and minimum WTA to not participate. They do not find evidence of an interaction between ambiguity and the WTA/WTP ratios, but this is but one of the first experiments to explore ambiguity's role in this regard. Understanding why WTA and WTP measures differ so much has important practical implications, and the search for the answer certainly cannot exclude the role that nonEU preferences might have in the answer.

Our final point regarding valuation is that econometric methods could be adapted to the problem of endogenous risk. Statistical measures are available to test for endogeneity of risks and this can be important in valuation of risk changes. If risk levels that are faced by individuals are truly endogenous, then it would not be appropriate to treat them as exogenous in econometric models, regardless of whether they are to be used within an EU or non-EU framework. Tests for exogeneity are quite common in econometrics, yet this type of test is not common when studying environmental risks. The key econometric issue, presuming that perceived risks are central in explaining behavior, is whether these risks vary independently from other variables in the model. Engle et al. (1983) define conditions where a set of variables is weakly exogenous in the context of a full model: this boils down to whether the full model is equally efficient by using a conditional or full, joint distribution for the set of variables. For example, suppose that we are modeling drinking water in the presence of health risks, as a function of perceived health risk, income, and other variables. One can imagine a possible relationship between the formation of risk perceptions and income, as income may also relate to education, concerns about paying for health care, etc. It would seem prudent to test for weak exogeneity.

Suppose that tests show that risks are endogenous. If so, there are grave concerns about moral hazard issues and the role of markets or insurance (Heal and Kriström, 2002); uncovering estimates of risk may be difficult, involving elicitation of perceived and subjective risks. What then? We would recommend that researchers explore a model where perceived risks are potentially dependent on key variables, and then feed predicted values of the risk back into the behavioral model. Those variables might be age, gender, and factors that probably also determine whether a person purchases health insurance (e.g., income, family size, past health history). Such modeling of perceived risks is certainly not new, or beyond researchers' capabilities: Viscusi and Evans (1998) jointly estimated preferences for product safety decisions and risk perceptions, and Riddel and Shaw (2006) feed predicted subjective risks into their behavioral model of the decision to move away from routes carrying high-level radioactive wastes.

What has not been done, to our knowledge, is then to further explore whether the predicted values of the modeled risks are consistent with EU- or SEU-type behavior. This is going to be difficult, as conclusions about the validity of EU or SEU assumptions rely on convincing modeling of the behaviors over the entire region of subjective risks, not just some portion. In other words, we might elicit subjective risks only in some portion of a range of probabilities, but find that our endogenous risk model predicts quite poorly outside this range. However, for policy purposes we might be on safe ground, as marginal risk changes from programs to reduce risk are much more likely than huge changes in risk.

\subsection{Optimal resource management}

Another area in which non-EU preferences are beginning to be applied is in the analysis of optimal resource management. Analysis of optimal resource management typically makes use of the dynamic optimization frameworks of optimal control and dynamic programming or their 
stochastic counterparts. Building on Kreps and Porteus (1978), Epstein and Zin (1989) provide a tractable framework for carrying out dynamic optimization without assuming either additively separable welfare across time or expected utility preferences outcomes. Their model, therefore, could accommodate preferences that are nonlinear in probabilities. The Epstein and Zin framework might be used in applied analysis, but there are relatively few such applications. In the area of natural resource management, Knapp and Olson (1996), Peltola and Knapp (2001), and Epaulard and Pommeret (2003) apply the Epstein and Zin formulation, though in each case the attention is primarily on separating time preferences from risk attitudes without relaxing the expected utility formulation.

Another thread of interest is the use of robust control methods as has been carried out by RosetaPalma and Xepapadeas (2004). Robust control is an optimization approach that is widely employed in engineering and optimizes relative to the worst-case scenario. This is particularly appropriate when designing, for example, a bridge, since "getting it right" almost all the time is more important than "getting it right" on average. Hansen and Sargent (e.g., Hansen et al., 2006) have begun to advocate the use of robust control in macroeconomics, and motivate it as an implementation of the MMEU of Gilboa and Schmeidler (1989). Roseta-Palma and Xepapadeas have applied the same logic to the resource management problems in the areas of water (2004) and fisheries (Xepapadeas and Roseta-Palma, 2003). The jury is still out on whether robust control is appropriate in an economic context (Sims, 2001). However, if it is applicable anywhere, then we believe that it is certainly so in many problems of environmental and resource management.

\section{Summary and some caveats}

In this paper, we have summarized some of the evidence pertaining to the axioms of the expected utility and subjective expected utility hypotheses, making this accessible to environmental economists who might not be looking at the more general literature on risk and uncertainty and perhaps having difficulty making the connections. Consensus that the EU and SEU models fail has not yet been reached, but it appears that many decision and uncertainty theorists are leaning away from them (Fishburn, 1988; Starmer, 2000). Should we (environmental and resource economists) care one way or the other? We believe so.

As Table 2 makes clear, for many of the problems we study the conditions are ripe for departures from the EU framework. Low probability high-consequence events are prevalent throughout environmental and natural resource economics. We often deal with problems in which scientific understanding is weak and the public may face significant ambiguity. So, we believe, resource economists should take note of the new empirical and theoretical approaches that are being developed to handle departures from the EU framework.

However, we do not want to give the impression that this is the only or most important conceptual challenge that our discipline faces. As reviewers and an editor reminded us, it is important to remember two things. First, there are many failed assumptions that can be reassessed, and where having done so, behavior can be better explained; usually these assumptions have little or nothing to do with fundamental tenants of the EU. The question of rationality lurks behind all modeling of behavior, and Cherry et al. (2003) explore whether rationality with market choices spills over to choices involving non-market situations; they find evidence that it does. They do not find evidence that preferences for lotteries change because of the context. A large body of research has been devoted to the stability of preferences, much of it within the rubric of certainty. Thaler (1981) has contributed to this vast literature, finding many inconsistencies in preferences. Jack Knetsch, as another example, demonstrated many times that preferences under certainty may differ depending 
on whether the individual faces losses or gains (see Knetsch, 1989; his discussion of some of these in Knetsch, 1995). Allowing for such differences can help explain behaviors otherwise puzzling. Another example of inconsistencies in preferences relates to discounting: people may change their private rate of discount depending on the length of time being considered or other contexts (Lowenstein and Prelec, 1992). Finally, Loomes (2006b) provides a powerful critique of almost all models of rationality (including his own) arguing that apparent violations of the EU can be explained simply by the inability to make fine distinctions in multi-attribute choices.

Yet another example of an invalid assumption that carries over to the EU and any other model is that there are no transactions costs in making decisions. For example, there are many instances in which individuals fail to purchase insurance when the basic EU model would suggest they should. Such discrepancies can often be reconciled by assuming that there are transactions costs that drive a wedge between EU maximization and observed behavior. Kunreuther and Pauly (2004) consider the following paradox: if the probability of an earthquake next year is $1 / 250$ or greater, and the ratio of the insurance premium to the damage is less than or equal to $1 / 250$, then one would expect to see risk neutral or averse people making purchases of this actuarially fair insurance. They do not often see such purchases being made. They maintain that individuals do try to maximize expected utility, but they face the cost of discovering the true probability of these events, and this creates a block to the purchase. Like imperfect information, the cost of obtaining and processing information may be the root cause of inconsistency with EU predictions in actual market settings.

The second reminder relates to the fact that EU may work well in some situations, and that non-EU models may also fail to adequately predict behavior. If probabilities are well-understood, perhaps when they fall in the middle range (e.g., a fair coin toss), and the magnitude of difference between losses and gains is quite small in some gamble, the EU may adequately predict what choices people will make. Some have argued that if financial incentives (e.g., scoring approaches) are used on survey or experimental subjects, they will provide subjective risk assessments that are consistent with those based on so-called experts, and once that has been achieved, the EU is the acceptable model to apply to the data.

Markets that function well to reward and penalize those making gambles have been shown to reduce violations of the EU (e.g., Evans, 1997). This suggests a role in some risk allocation contexts for options contracts. However, Dow and Werlang (1992) show that ambiguity can diminish the actual trade in such risk-hedging instruments. And, of course, the focus of this paper is on environmental and resource issues, which are largely characterized by non-market goods.

Neither of the non-EU models we favor predict all the choice patterns that are frequently observed. For example, Quiggin's RDEU framework implies that individuals who overweight low probability outcomes are pessimists who will avoid these lotteries, yet Battalio et al. (1990) find no support for the RDEU's predicted behaviors. Further, RDEU is designed to maintain transitivity, but Loomes (2006b) notes that problems in which violations of transitivity are common. Similarly, Machina's (1982) fanning out model precludes behavior consistent with "fanning in," but some people exhibit that.

The problem with some non-EU alternatives rests with the fact that the EU is usually a special case. Much of the behavior inconsistent with the EU, therefore, will also be inconsistent with its non-EU parents.

\section{Final thoughts}

For environmental policies the problem of ambiguity is often central and our normative analysis should appreciate its importance. We offered the example of climate change, and as 
Faucheux and Froger (1995, p. 31) point out, "global environmental problems have no historical precedents... This means that the information on which decisions are made is most often a nonprobabilistic kind." Therefore, as economists enter into these policy debates, we should keep in mind that our recommendations are only as correct as the axiomatic foundation of the underlying decision model (Woodward and Bishop, 1997).

In 1738, Daniel Bernoulli solved the St. Petersburg paradox by inventing the principle of expected utility. Today we look with puzzlement at the response of Daniel's cousin Nicholas Bernoulli who continued to look in vain for a single fair price for the game based on its expected value. After retelling this story, Harless and Camerer (1994) ask, "Might future economists find it [equally] peculiar that twentieth century economists held firmly to EU in the face of the Allais paradox and other violations?" (p. 1284). There may be no general theory of decision making under uncertainty. Loomes (2006b) recently states "if [his] model of the data generating process is correct, there can be no descriptively adequate general theory of risky choice which is rational..." [p. 2]. Still, some otherwise puzzling outcomes can be explained by alternatives to the EU models, and we believe that environmental and resource economists should begin to pay attention to these alternative models.

\section{Acknowledgements}

Shaw holds a joint appointment with Texas A\&M's Department of Recreation, Parks and Tourism Sciences and acknowledges their support of this research. In general, we have greatly benefited from having discussions on risk and uncertainty with David Bessler, Trudy Cameron, J.R. DeShazo, Nicholas Flores, Paan Jindapon, William Neilson, Mary Riddel, Antony Scott, and Kerry Smith. We also appreciate helpful comments from the editor of, and two reviewers for, this journal. Michele Zinn made sure our final paper was grammatically correct. A considerably earlier version of the paper was presented by Woodward as a selected paper at the 1998 meeting of the American Agricultural Economics Association, August 2-5, 1998, Salt Lake City, Utah. Some of this work was supported by an exploratory grant from the National Science Foundation.

\section{References}

Allais, P.M., 1953. Le Comportement de l'Homme Rationnel Devant Le Risque: Critique des Postulats et Axiomes de L'Ecole Americaine. Econometrica 21 (4), 503-546.

Anand, P., 1993. The Philosophy of Intransitive Preference. Economic Journal 103 (417), 337-346.

Arrow, K.J., Hurwicz, L., 1972. An optimality criterion for decision-making under ignorance. In: Carter, C.F., Ford, J.L. (Eds.), Uncertainty and Expectations in Economics: Essays in Honour of G.L.S. Shackle. Basil Blackwell, Oxford.

Ayong Le Kama, A., Schubert, K., 2004. Growth, environment and uncertain future preferences. Environmental and Resource Economics 28 (1), 31-53.

Baker, J., Shaw, W.D., Bell, D., Brody, S., Neilson, W., Riddel, M., Woodward, R.T., 2007. The role of perceived risks of hurricanes in intended moving and choice location models. Discussion paper, Texas A\&M University.

Battalio, R.C., Kagel, J.H., Jiranyakul, K., 1990. Testing between alternative models of choice under uncertainty: some initial results. Journal of Risk and Uncertainty 3 (1), 25-50.

Bernasconi, M., 1998. Tax evasion and orders of risk aversion. Journal of Public Economics 67, $123-134$.

Bleichrodt, H., Pinto, J.L., November, 2000. A Parameter-free elicitation of the probability weighting function in medical decision analysis. Management Science 46 (11), 1485-1496.

Bosch-Domènech, A., Silvestre, J., Dec., 1999. Does risk aversion or attraction depend on income? Economics Letters 65, 265-273.

Brown, T.C., 2004. Loss aversion without the endowment effect, and other explanations for the WTA-WTP disparity. Journal of Economic Behavior \& Organization 57 (3), 367-379. 
Camerer, C., Weber, M., 1992. Recent developments in modeling preferences: uncertainty and ambiguity. Journal of Risk and Uncertainty 5 (4), 325-370.

Cameron, T., 2005. Updated subjective risks in the presence of conflicting information: application to climate change. Journal of Risk and Uncertainty 30 (1), 63-97.

Chavas, J.-P., Mullarkey, D., 2002. On the valuation of uncertainty in welfare analysis. American Journal of Agricultural Economics 84 (1), 23-38.

Cherry, T.L., Crocker, T.D., Shogren, J.F., 2003. Rationality Spillovers. Journal of Environmental Economics and Management 45, 63-84.

Chew, S.-H., Karni, E., Safra, Z., 1987. Risk aversion in the theory of expected utility with rank dependent probabilities. Journal of Economic Theory 42 (2), 370-381.

Chichilnisky, G., Heal, G., Fall, 1993. Global environmental risks. Journal of Economic Perspectives 7 (4), 65-86.

Chivers, J., Flores, N.E., November, 2002. Market failure in information: the national flood insurance program. Land Economics 78 (4), 515-521.

Chow, C.C., Sarin, R.K., 2001. Comparative ignorance and the Ellsberg Paradox. Journal of Risk and Uncertainty 2, 129139.

Crocker, T.D., Forster, B.A., Shogren, J.F., 1991. Valuing potential groundwater protection benefits. Water Resources Research 27 (1), 1-6.

Dow, J., Werlang, S.R.C., 1992. Uncertainty aversion, risk aversion, and the optimal choice of portfolio. Econometrica 60 (1), 197-204.

Eisenberger, R., Weber, M., 1995. Willingness to pay and willingness to accept for risky and ambiguous lotteries. Journal of Risk and Uncertainty 10, 223-233.

Ellsberg, D., 1961. Risk, ambiguity and savage axioms. Quarterly Journal of Economics 75 (4), 643-679.

Engle, R., Hendry, D., Richard, J., 1983. Exogeneity. Econometrica 51, 277-304.

Epaulard, A., Pommeret, A., 2003. Optimally eating a stochastic cake: a recursive utility approach. Resource and Energy Economics 25 (2), 129-139.

Epstein, L.G., 1999. A definition of uncertainty aversion. Review of Economic Studies 66 (3), 579-608.

Epstein, L.G., Zin, S.E., 1989. Substitution, risk aversion, and the temporal behavior of consumption and asset returns: a theoretical framework. Econometrica 57 (4), 937-969.

Evans, D., 1997. The role of markets in reducing expected utility violations. Journal of Political Economy 105, 622-636.

Faucheux, S., Froger, G., 1995. Decision-making under environmental uncertainty. Ecological Economics 15, $29-42$.

Fishburn, P.C., 1988. Expected utility an anniversary and a new era. Journal of Risk and Uncertainty 1, 267-283.

Fox, C.R., Tversky, A., 1995. Ambiguity aversion and comparative ignorance. Quarterly Journal of Economics 110, 585603.

Fox, C.R., Weber, M., May, 2002. Ambiguity aversion, comparative ignorance, and decision context. Organizational Behavior and Human Decision Processes 88 (1), 476-998.

Gilboa, I., 1987. Expected utility with purely subjective non additive probabilities. Journal of Mathematical Economics 16 (1), 65-88.

Gilboa, I., Schmeidler, D., 1989. Maxmin expected utility with non-unique prior. Journal of Mathematical Economics 18, $141-153$.

Gonzalez, R., Wu, G., 1999. On the shape of the probability weighting function. Cognitive Psychology 38, 129-166.

Graham, D.A., 1981, December. Cost benefit analysis under uncertainty. American Economic Review 71, 715-725.

Graham, D.A., 1992. Public expenditure under uncertainty: the net-benefit criteria. American Economic Review 82 (4), $822-846$.

Hammond, P.J., 1981. Ex ante and ex post welfare optimality under uncertainty. Economica 48 (191), 235-250.

Hansen, L.P., Sargent, T.J., Turmuhambetova, G., Williams, N., 2006. Robust control and model misspecification. Journal of Economic Theory 128 (1), 45-90.

Harless, D.W., Camerer, C.F., 1994. The predictive utility of generalized expected utility theories. Econometrica 62 (6), 1251-1289.

Harrison, Glenn, Rutström, E., 2006. Eliciting subjective beliefs about mortality risk orderings. Environmental and Resource Economics 33, 325-346.

Heal, G., Kriström, B., 2002. Uncertainty and climate change. Environmental and Resource Economics 22, 3-39.

Heath, C., Tversky, A., 1991. Preference and belief: ambiguity and competence in choice under uncertainty. Journal of Risk and Uncertainty 4, 5-28.

Hicks, J.R., 1939. Value and capital: an inquiry into some fundamental principles of economic theory. The Clarendon press, Oxford.

Hogarth, R.M., Kunreuther, H., 1985. Ambiguity and insurance decisions. American Economic Review 75 (2), 386-390. 
Horowitz, J.K., McConnell, K.E., 2003. Willingness to accept, willingness to pay and the income effect. Journal of Economic Behavior and Organization 51, 537-545.

Howarth, R.B., 1997. Sustainability as opportunity. Land Economics 73 (4), 569-579.

Howard, R.A., 1992. In praise of the old time religion. In: Edwards, W. (Ed.), Utility Theories: Measurements and Applications. Studies in Risk and Uncertainty, 3. Kluwer Academic, Norwell, Mass. and Dordrecht.

Kahneman, D., Tversky, A., 1979. Prospect theory: an analysis of decision under risk. Econometrica 47 (2), $263-292$.

Kaldor, N., 1939. Welfare propositions and interpersonal comparisons of utility. Economic Journal 49, 549-552.

Karni, E., Safra, Z., 1995. The impossibility of experimental elicitation of subjective probabilities. Theory and Decision 38, 313-320.

Keppe, H.-J., Weber, M., 1995. Judged knowledge and ambiguity aversion. Theory and Decision 39 (1), 51-77.

Kelsey, D., 1993. Choice under partial uncertainty. International Economic Review 34 (2), 297-308.

Kelsey, D., Quiggin, J., 1992. Theories of choice under ignorance and uncertainty. Journal of Economic Surveys 6 (2), 133-153.

Kivi, P., Shogren, J.F., 2005. Ambiguity and Food Safety. Revised discussion paper, Department of Economics and Finance, University of Wyoming.

Knapp, K.C., Olson, L.J., 1996. Dynamic resource management: intertemporal substitution and risk aversion. American Journal of Agricultural Economics 78 (4), 1004-1014.

Knetsch, J.L., 1989. The endowment effect and evidence of nonreversible indifference curves. American Economic Review 79:, 1277-1284.

Knetsch, J.L., 1995. Assumptions, behavioral findings, and policy analysis. Journal of Policy Analysis and Management 14 (1), 68-78.

Knight, F.H., 1921. Risk, uncertainty and profit. Houghton, Mifflin Co., Boston.

Kreps, D.M., Porteus, E.L., 1978. Temporal resolution of uncertainty and dynamic choice theory. Econometrica 46 (1), 185-200.

Krupnick, A.J., Markandya, A., Nickell, E., 1993. The external costs of nuclear-power-ex ante damages and lay risks. American Journal of Agricultural Economics 75 (5), 1273-1279.

Kunreuther, H., Spring. 1976. Limited knowledge and insurance protection. Public Policy 24 (2), 229-257.

Kunreuther, H., Pauly, M., 2004. Neglecting disaster: why don't people insure against large losses? Journal of Risk and Uncertainty 28 (1), 5-21.

Leland, H.F E., 1968. Saving and uncertainty: the precautionary demand for saving. In: Diamond, P., Rothschild, M. (Eds.), Uncertainty in Economics: Readings and Exercises. Harcourt Brace Jovanovich, Academic Press, San Diego.

Loomes, G., 2006a. (How) can we value health, safety and the environment? Journal of Economic Psychology 27 (6 (December)), 713-736.

Loomes, G., 2006b. Why there may be no rational, general, and descriptively adequate theory of decision under risk. Discussion paper, University of East Anglia (June version).

Loomes, G., Sugden, R., 1982. Regret theory: an alternative theory of rational choice under uncertainty. The Economic Journal 92 (December), 805-824.

Lowenstein, G., Prelec, D., 1992. Anomolies in intertemporal choice: evidence and interpretation. Quarterly Journal of Economics 107, 573-597.

Machina, M.J., 1982. Expected utility analysis without the independence axiom. Econometrica 50 (2), $277-323$.

Machina, M.J., Summer, 1987. Choice under uncertainty: problems solved and unsolved. Journal of Economic Perspectives 1 (1), 121-154.

Machina, M.J., 1994. "Review of: Generalized expected utility theory: the rank dependent model (Norwell, Mass.: Kluwer Academic)." Journal of Economic Literature 32(3), 1237-1238.

Machina, M.J., 2001. Payoff kinks in preferences over lotteries. Journal of Risk and Uncertainty 23 (3), $207-260$.

McFadden, D., 1999. Rationality for economists? Journal of Risk and Uncertainty 19 (13), 73-105.

Neilson, W.S., Winter, H., 1997. On criminals' risk attitudes. Economics Letters 55 (1), 97-102.

Oliver, A., 2003. Testing rank-dependent utility theory for health outcomes. Health Economics 12, 863-871.

Peltola, J., Knapp, K.C., 2001. Recursive preferences in forest management. Forest Science 47 (4), $455-465$.

Prelec, D., 1999. Probability weighting functions. Econometrica 66, 497-527.

Quiggin, J., 1982. A theory of anticipated utility. Journal of Economic Behavior and Organization 3 (4), $323-343$.

Quiggin, J., 1991. Supply response under proportional profits taxation. American Journal of Agricultural Economics 73 (1), 36-39.

Quiggin, J., 1992. Risk, self-protection and ex ante economic value-some positive results. Journal of Environmental Economics and Management 23 (1), 40-53.

Quiggin, J., 1993. Generalized expected utility theory: the rank-dependent model. Kluwer Academic Publishers, Boston. 
Quiggin, J., 2002. Risk and self-protection: a state-contingent view. Journal of Risk and Uncertainty 25 (2), $133-145$.

Quizon, J.B., Binswanger, H., Machina, M.J., 1984. Attitudes toward risk: further remarks. Economic Journal 94, 144148.

Ready, R.C., 1993. The choice of a welfare measure under uncertainty. American Journal of Agricultural Economics 75 (4), 896-904.

Ready, R.C., 1995. Environmental valuation under uncertainty. In: Bromley, D.W. (Ed.), The Handbook of Environmental Economics. Basil Blackwell, Cambridge, MA, pp. 568-593.

Riddel, M., Shaw, W.D., 2003. Option wealth and bequest values: the value of protecting future generations from the health risks of nuclear waste storage. Land Economics 79 (4), 537-548.

Riddel, M., Shaw, W.D., March, 2006. A theoretically consistent empirical model of non-expected utility: an application to nuclear waste transportation. Journal of Risk and Uncertainty 32 (2), 131-150.

Riddel, M., Dwyer, C., Shaw, W.D., August, 2003. Environmental risk and uncertainty: insights from yucca mountain. shaw. Journal of Regional Science 43 (3), 435-458.

Roseta-Palma, C., Xepapadeas, A., 2004. Robust control in water management. Journal of Risk and Uncertainty 29 (1), 21-34.

Savage, L.J., 1954. The foundations of statistics. Wiley, New York.

Schmeidler, D., 1989. Subjective probability and expected utility without additivity. Econometrica 57, 571-587.

Segal, U., 1987. The Ellsberg paradox and risk aversion: an anticipated utility approach. International Economic Review 28 (1 (February)), 175-202.

Segal, U., Spivak, A., 1990. First order versus second order risk aversion. Journal of Economic Theory 51 (1), $111-125$.

Shackle, G.L.S., 1952. Expectations in economics. The University Press, Cambridge, England.

Shackle, G.L.S., 1969. Decision order and time in human affairs. The University Press, Cambridge, England.

Shaw, W.D., Riddel, M., Jakus, P., 2005. Valuing environmental changes in the presence of risk: an update and discussion of some empirical issues, in: Folmer H. Tietenberg T. (Eds.), International Yearbook of Environmental and Resource Economics: A Survey of Current Issues 2005/2006. Edward Elgar Press, Cheltenham, UK.

Shaw, W.D., Nayga, R.M., Silva, A., May, 2006. Health benefits and uncertainty: an experimental analysis of the effects of risk presentation on auction bids for a healthful product. Economics Bulletin 4 (17), 1-8.

Shaw, W.D. et al., 2006. Incorporating perceived mortality risks from arsenic into models of drinking water behavior and the valuation of arsenic risk reductions. Presented at the U.S. Environmental Protection Agency Workshop on Mortality Risk, April, Washington, D.C.

Shogren, J.F., Crocker, T.D., 1991. Risk, self-protection and ex ante economic value. Journal of Environmental Economics and Management 20, 1-15.

Sims, C.A., 2001. Pitfalls of a minimax approach to model uncertainty. American Economic Review 91 (2), 51-54.

Slovic, P., 1987. Perception of risk. Science 236, 280-285.

Starmer, C., 2000. Developments in non-expected utility theory: the hunt for a descriptive theory of choice under risk. Journal of Economic Literature 38 (June), 332-382.

Sun, L., van Kooten, G.C., 2005. Fuzzy logic and preference uncertainty in non-market valuation. Discussion paper, Department of Economics, University of Victoria.

Thaler, R., 1981. Some empirical evidence on dynamic inconsistency. Econonomic Letters 8, 201-207.

Toman, M., 1998. Research frontiers in the economics of climate change. Environmental and Resource Economics 11 (3), 603-621.

Tversky, A., Kahneman, D., 1992. Advances in prospect theory: cumulative representation of uncertainty. Journal of Risk and Uncertainty 5 (4), 297-323.

Tversky, A., Wakker, P., November, 1995. risk attitudes and decision weights. Econometrica 63 (6), 1255-1280.

van Kooten, G.C., Krcmar, E., Bulte, E.H., 2001. Preference uncertainty in non-market valuation: a fuzzy approach. American Journal of Agricultural Economics 83 (3), 487-500.

Varian, H.R., 1992. Microeconomic analysis, third ed. W.W. Norton, New York.

Viscusi, W.K., 1989. Prospective reference theory: toward an explanation of the paradoxes. Journal of Risk and Uncertainty 2, 235-264.

Viscusi, W.K., November, 1997. Alarmist decisions with divergent risk information. Economic Journal 107, 1657-1670.

Viscusi, W.K., Evans, W.N., 1998. Estimation of revealed probabilities and utility functions for product safety decisions. Revue of Economics and Statistic 28-33.

Viscusi, W.K., Magat, W.A., Huber, J., 1999. Smoking status and public responses to ambiguous scientific risk evidence. Southern Economics Journal 66 (2), 250-270.

von Neumann, J., Morgenstern, O., 1944. Theory of Games and Economic Behavior. Princeton University Press, Princeton. 
Wakker, P., Deneffe, D., 1996. Eliciting von Neumann-Morgenstern utilities when probabilities are distorted or unknown. Management Science 42 (8), 1131-1150.

Wakker, P., Erev, I., Weber, E, 1994. Co-monotonic independence: the critical test between classical and rank-dependent utility theories. Journal of Risk and Uncertainty 9, 195-230.

Wald, A., 1950. Statistical decision functions. Wiley, New York.

White, R.R., 2001. Catastrophe options: an experiment in the management of catastrophic risk in the United States. Journal of Environmental Management 62, 323-326.

Woodward, R.T., Bishop, R.C., 1997. How to decide if experts disagree: uncertainty-based choice rules in environmental policy. Land Economics 73 (4), 492-507.

Xepapadeas, A., Roseta-Palma, C., 2003. Instabilities and Robust Control in Fisheries. Working Papers from Fondazione Eni Enrico Mattei \# 2003.110.

Yaari, M.E., 1987. The dual theory of choice under risk. Econometrica 55 (1), 95-115. 